\title{
Relevance of TP53 for CLL diagnostics
}

\author{
Mark A Catherwood, ${ }^{\oplus}$ David Gonzalez, ${ }^{2}$ David Donaldson, ${ }^{1}$ Ruth Clifford, ${ }^{3}$ Ken Mills, ${ }^{2}$ \\ Patrick Thornton ${ }^{4}$
}

'Haematology Department, Belfast Health and Social Care Trust, Belfast, UK

${ }^{2}$ Centre for Cancer Research and Cell Biology (CCRCB),

Queen's University Belfast, Belfast, UK

${ }^{3}$ Department of Haematology, University Hospital Limerick, Ireland

${ }^{4}$ Department of Haematology, Beaumont Hospital, Dublin, Ireland

\section{Correspondence to}

Dr Mark A Catherwood, Clinical Haematology, Belfast City Hospital, BHSCT, Belfast, BT9 7AB, UK ; mark.catherwood@ belfasttrust.hscni.net

Received 24 November 2018 Revised 14 January 2019 Accepted 14 January 2019

Published Online First

2 February 2019
Check for updates

(C) Author(s) (or their employer(s)) 2019. No commercial re-use. See rights and permissions. Published by BMJ.

To cite: Catherwood MA, Gonzalez D, Donaldson D, et al. J Clin Pathol

2019:72:343-346

\section{ABSTRACT}

TP53 disruption in chronic lymphocytic leukaemia (CLL) is a well-established prognostic marker and informs on the appropriate course of treatment for patients. TP53 status is commonly assessed by fluorescence in situ hybridisation for del(17p) and Sanger sequencing for TP53 mutations. At present, current screening methods for TP53 mutations fail to detect diagnostically relevant mutations potentially leading to inappropriate treatment decisions. In addition, low levels of mutations that are proving to be clinically relevant may not be discovered with current less sensitive techniques. This review describes the structure, function and regulation of the TP53 protein, the mutations found in cancer and CLL, the relevance of TP53 disruption in CLL and the current screening methods for TP53 mutations including nextgeneration sequencing.

\section{INTRODUCTION}

\section{Tumour suppressor p53 (TP53) gene}

Tumour suppressor p53 (TP53) was first identified in 1979 when two independent groups published their findings on the interaction of a cellular protein of approximately $53-55 \mathrm{kDa}$ and a large T-antigen of the Simian virus (SV40). ${ }^{12}$ P53 was initially thought to act as an oncogene and it was only in the late 1980s that it was correctly assigned as a tumour suppressor gene and then coined as the 'Guardian of the Genome'. ${ }^{3}$

The protein p53 contains 393 amino acids and is encoded by the TP53 gene in humans. It is located on the short arm (p) of chromosome 17 (17p13.1) and possesses 11 exons, of which 10 are coding (figure 1).

\section{STRUCTURE AND FUNCTION}

$\mathrm{P} 53$ is a sequence-specific DNA binding protein that regulates transcription. The protein consists of two N-terminal transactivation domains with a conserved proline-rich domain, a central DNA-binding domain followed by a C-terminus. This encodes its nuclear localisation signals and a domain essential for transcriptional activity.

The p53 protein level is low in normal cells as it is maintained by a series of regulators such as mouse double minute 2 (MDM2) (E3 ubiquitin protein ligase), which facilitates ubiquitin-mediated degradation. ${ }^{4}$ The role of p53 is to control cell proliferation. It is upregulated in response to cellular stress such as DNA damage and activation of oncogenes. When activated, p53 protein levels increase and cell phenotypes change to include apoptosis and elevated DNA repair. ${ }^{5}$

The $\mathrm{p} 53$ protein, via two transactivation domains, binds strongly to several specific DNA sequences. ${ }^{67}$
MDM2, a negative regulator of $\mathrm{p} 53$, binds to the transactivation domain inducing an alpha-helical conformation thereby inhibiting transcription of p53. ${ }^{8}$ By translocating these genes during periods of cell stress, they become active, producing proteins involved in cell cycle progression and apoptosis. ${ }^{9}$ During genotoxic stress, p53 protein is phosphorylated by ataxia telangiectasia mutated kinase and prevented from undergoing MDM2-mediated degradation (figure 2). Under oncogenic stress, p53 is protected from degradation by p14ARF (alternate reading frame tumour suppressor) protein.

While p53 has a number of functions, the ability to promote cell cycle arrest and apoptosis are the most comprehensively understood. It has been well recognised that p53 is capable of upregulating the cyclin-dependent kinase inhibitor, CDKN1A. It is also well established that the transcriptional activity of p53 is tissue specific and prominent in lymphocytes. ${ }^{10}$ In addition, p53 can trigger apoptosis by relying on the induction of proapoptotic $B C L-2$ family members facilitating caspase activation and cell death. ${ }^{11}$

\section{ORIGINS OF P53}

TP53 is a member of a broader gene family including TP63 and TP73. Unlike TP53, both TP63 and TP73 do not have tumour suppressive capabilities. In eukaryotes, the p53 protein sequence is relatively conserved; however, TP53 has evolved by increasing gene dosage.

At first, this critical anticancer gene was believed to be an oncogene, as it was overexpressed in many cancers including breast and lung cancer. ${ }^{12-14}$ Subsequently, it was discovered that TP53 was mutated in half of all human cancers, and loss of regulatory function of $\mathrm{p} 53$ led to oncogenesis. ${ }^{15}$ Germline TP53 mutations are pathogenic in cases of Li-Fraumeni syndrome, a hereditary cancer predisposition syndrome. ${ }^{16}$

The majority of tumour suppressor genes are frequently inactivated by deletions or truncating mutations causing a loss of protein expression. In contrast, the TP53 gene is unique in comparison to other tumour suppressor genes as inactivation on both alleles is not required to eliminate p53 function. Loss of function of TP53 is considered a major event in tumorigenesis and is also linked to chemotherapy resistance and a poor prognosis in many cancers. ${ }^{15}$

The most common and best characterised mutations in TP53 are missense mutations within the DNA-binding domain. These account for approximately $75 \%$ of mutations and of these, almost $25 \%$ occur within six hotspot codons. Interestingly, $25 \%$ of TP53 mutations are non-sense or frameshift mutations, while the remainder are splice site single nucleotide variants and in-frame indels. Inactivation 


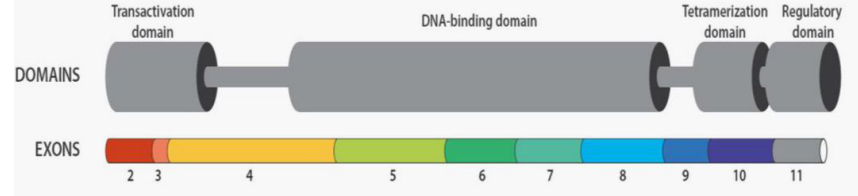

Figure 1 Schematic structure of TP53 gene. The TP53 gene is located on the short arm (p) of chromosome 17 (17p13.1) and possesses 11 exons, of which 10 are coding.

of the second TP53 allele occurs most commonly through loss of heterozygosity. ${ }^{17}$

A significant body of evidence suggests that certain mutant TP53 alleles have a gain of function property. This was first suggested over 25 years ago with the introduction of mutant p53 cells that gave rise to a new phenotype distinct from null cells. ${ }^{18}$

As previously stated, the TP53 gene is mutated in half of all human cancers; however, different tumours show a wide spectra of TP53 mutations. Two broad categories of mutant p53 effects have been described:

1. Those affecting amino acids that contact DNA preventing wild-type transcriptional activity with major disruption to the protein.

2. Those disrupting the three-dimensional structure of the protein.

Although mutations in this gene are most commonly seen in solid tumours, haematological cancers possess these mutations at a lower rate. In contrast, chronic lymphocytic leukaemia (CLL), a common form of adult leukaemia, contains an unusually high number of TP53 aberrations with well-documented evidence for their role in disease pathogenesis. ${ }^{19} 20$

\section{Chronic lymphocytic leukaemia}

CLL is the most common leukaemia in adults in the Western world and is characterised by clonal expansion of CD5+ B cells, derived from healthy CD5 + B cells throughout the blood, lymphoid tissues and bone marrow of patients. ${ }^{21}$ CLL has a highly variable presentation and clinical course. The majority of patients at presentation are asymptomatic, have indolent disease and are managed on an active surveillance approach without requiring treatment for many years. A proportion of patients progress and require therapy shortly after diagnosis and can have a rapidly progressive disease leading to early death. This clinical heterogeneity highlights the need for both prognostic and predictive markers in CLL. ${ }^{22}$

Considerable advances have been made over the past decade using genome-wide sequencing approaches to decipher the genetic complexity of CLL. However, the key therapy decision-making biomarkers in CLL are TP53 aberrations: chromosomal defects of 17 p13 and TP53 gene mutations. ${ }^{2324}$

\section{TP53 aberrations in patients with CLL}

TP53 gene defects in CLL were first described in the early 1990s and the association with inferior clinical survival was established. ${ }^{19}$ Initially, the loss of the TP53 locus was not considered to be an important event in the era of karyotyping. ${ }^{25}$ However, this was to change with the publication of Dohner's hierarchical CLL classification in $2000 .^{26}$ This firmly established the inferior survival of patients with deletions of $17 \mathrm{p} 13$ (del(17 p)). This was subsequently confirmed in other studies and implemented into routine practice. ${ }^{27}$ While karyotyping required dividing cells, Dohner's classification used fluorescence in situ hybridisation (FISH). FISH uses fluorophore-labelled DNA probes that hybridise to specific DNA sequences that allows the identification of deletions, additions and translocations. In contrast, TP53 mutational status was not initially assessed routinely in CLL diagnostics as it was assumed that TP53 mutations did not occur in the absence of del(17 p). ${ }^{28-30}$ With further studies, it became clear that $\operatorname{del}(17 \mathrm{p})$ is usually accompanied by TP53 mutations in CLL, and studies have shown that both can occur independently with

\section{Cellular stresses}
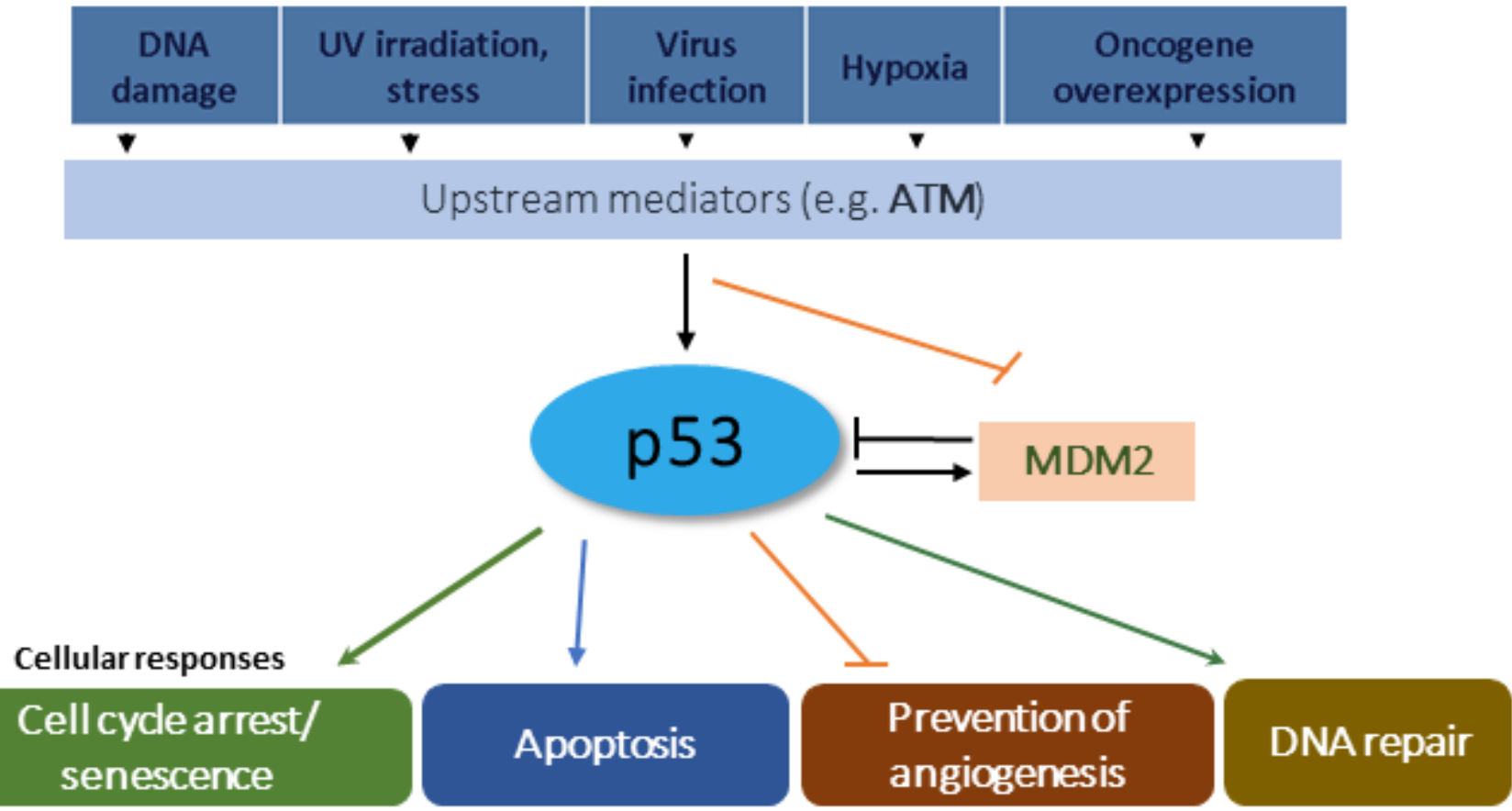

Figure 2 p53 function and regulation. ATM, ataxia telangiectasia mutated; MDM2, mouse double minute 2; UV, ultraviolet. 


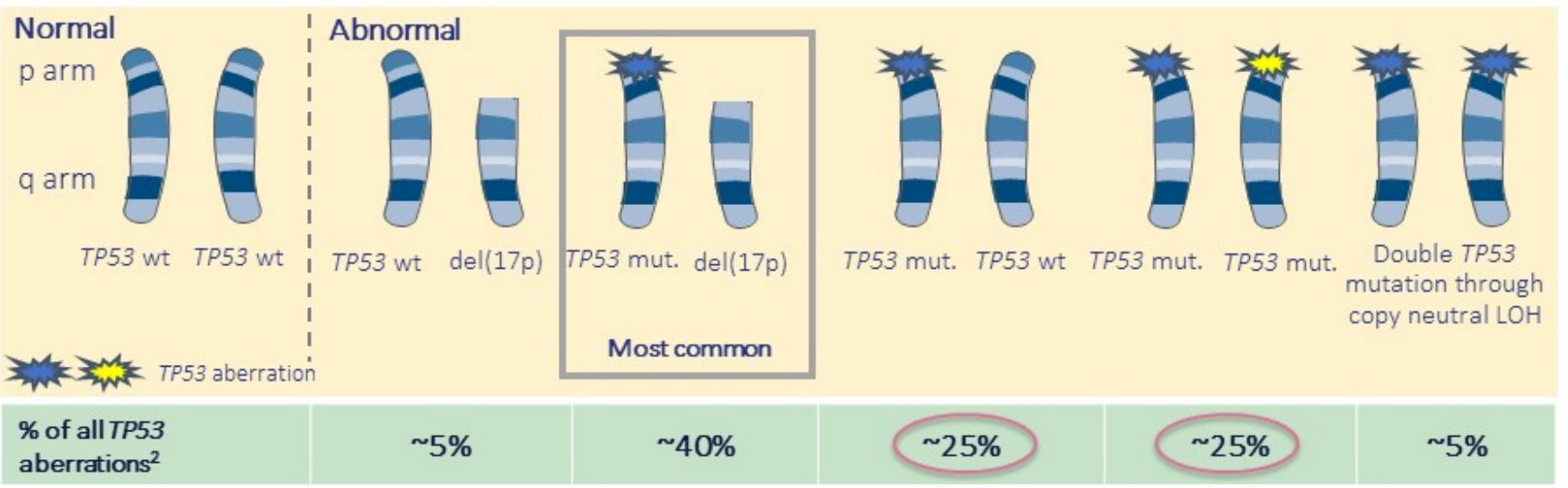

Figure 3 TP53 defects: loss of p53 function in chronic lymphocytic leukaemia can occur due to del(17 p) and/or TP53 variants. The most common cause of TP53 aberrations results in the combination of del(17 p) and TP53 mutation.

the frequency dictated by the particular patient cohort studied and the methodology used.

The frequency of TP53 mutations are low in treatment-naive patients (approximately 10\%) but this increases (up to 25\%-50\% depending on the study) in patients with disease progression and treatment refractory patients suggesting that these alterations are mostly acquired and provide a mechanism of resistance. ${ }^{30}$

In general, $90 \%$ of patients with $\operatorname{del}(17 \mathrm{p})$ carry a mutation and up to $65 \%$ of patients with a TP53 mutation have del(17 p). ${ }^{31-33}$ Patients with a monoallelic TP53 mutation also have an inferior progression-free and overall survival. ${ }^{3133}$ Of all patients with TP53 disruption, mutations and deletions occur together in the majority of patients with monoalleleic TP53 mutations accounting for another $40 \%$ of patients, monoalleleic deletions and also mutations with copy neutral loss of heterozygosity account for a minority of patients (figure 3 ).

\section{TP53 AS A TREATMENT RESPONSE PREDICTOR}

For more than a decade, chemoimmunotherapy in the form of fludarabine, cyclophosphamide and rituximab was the conventional first-line regimen in fit patients providing a high response rate, improved progression-free survival and an impact on overall survival for the first time in CLL. Not all patients benefit from this treatment, with up to $25 \%$ of patients relapsing within 24 months, fulfilling the definition for chemorefractoriness. ${ }^{34}$ Fludarabine, a purine nucleoside analogue, interferes with DNA synthesis and repair in dividing and non-dividing cells and therefore requires a functional p53 protein to be effective. The presence of TP53 aberrations reduces progression-free survival due to chemotherapy resistance. ${ }^{29} 30$ The advent of novel treatment options in CLL targeting the B-cell receptor and antiapoptotic molecules targeting BCL-2 have proved beneficial in the treatment of patients with TP53 aberrations providing alternative methods for cell death. ${ }^{35-37}$ This therefore highlights the need for accurate assessment of TP53 defects to identify patients who will benefit from novel therapies.

\section{CURRENT TESTING REGIMENS IN ROUTINE PRACTICE}

Current guidelines recommend assessment of TP53 aberrations in patients requiring therapy. Reassessment at each pretreatment time point should be undertaken as clonal evolution can occur. ${ }^{24}$ As already stated, the assessment of $\operatorname{del}(17$ p) by FISH is routinely performed. The cut-off for a positive result varies within laboratories with the widely accepted threshold that $>20 \%$ of cells should contain del(17 p) to be a clinically relevant clone. ${ }^{38}$ Sanger sequencing is widely used for TP53 mutational analysis; however, it may misclassify cases of TP53 mutations as wild type when variants with allelic burdens below the detection limit of Sanger sequencing are present. With the implementation of NGS, large amounts of DNA can be sequenced in parallel at a lower cost than the gold standard Sanger sequencing. Updated guidelines from the TP53 network of European Research Initiative on CLL (ERIC; www.ericcll.org) suggest a threshold of $10 \%$ allelic burden for reporting mutations detected by NGS. ${ }^{39}$

Targeted NGS panels are also available whereby custom probes are designed to target genes/regions of interest within the genome with much greater sensitivity. This targeted approach facilitates a greater depth of sequencing as a much smaller percentage of the genome is interrogated. ${ }^{4041}$ This technique has led to improved knowledge on gene mutations and signalling pathways by screening large cohorts. ${ }^{42}{ }^{43}$ For targeted NGS, if solely one time point is available, intraclonal dynamics can be studied using the variant allele frequency to infer the timing of mutations. $^{43}$

The general principles of targeted NGS panels are based on sequencing an amplified DNA template. As with other applications, the DNA template is a double-stranded DNA construct consisting of short fragments of DNA flanked by adapters of known sequence. Illumina sequencing is the most broadly used NGS technique and consists of a solid phase amplification of the DNA template on a flow cell with subsequent sequencing by synthesis. ${ }^{44}$ Novel approaches such as capture-based sequencing allows the simultaneous detection of somatic mutations, copy number variations and chromosomal translocations. ${ }^{45}$ As with all technologies, several limitations exist and one of the major limitations of NGS is the lack of standardised bioinformatics pipelines and the requirements to handle large data sets. ${ }^{46}$

As TP53 mutational status has a major impact on treatment decisions, international collaborations such as ERIC have developed a network of TP53 reference centres within various countries. ERIC aims to provide standardisation and harmonisation of diagnostic strategies for TP53 mutational assessment resulting in robust testing strategies and offering quality assurance schemes.

The introduction of NGS also allows the detection of TP53 mutated subclones. Subclonal TP53 is the term used to describe variants that are not present in the entire tumour population. This has great clinical relevance in CLL as the disease progresses, different leukaemic cells acquire mutations leading to numerous subclones developing. The subclones are intrinsically linked to their environment, and any changes to this environment such as 
chemotherapy, create changes in the cells, allowing outgrowth of resistant clones. ${ }^{20}$ This is particularly relevant in CLL as TP53 mutated subclones occur in a significant proportion of cases and have the same unfavourable prognostic impact as that of clonal TP53 defects. ${ }^{47} 48$

In conclusion, in CLL, the inactivation of the TP53 gene by either a deletion or a mutation has a negative impact on the disease course for patients. Detectable TP53 aberrations are markers of chemorefractoriness, and consequently, treatment decisions are based on this finding. It is a now accepted practice that TP53 aberrations should be tested before each treatment decision, and NGS represents an ideal technique for mutation assessment and has the additional capability and advantage above historical techniques to detect clinically relevant mutated subclones.

\section{Handling editor Des Richardson.}

Acknowledgements The authors acknowledge members of the Haematology Department, Belfast City Hospital for helpful discussions.

Contributors MAC wrote the manuscript and prepared all figures. DG, RC, KM, DD and PT contributed to the writing of the manuscript.

Funding KM is funded by Leukaemia and Lymphoma Northern Ireland (LLNI).

Competing interests None declared.

Patient consent for publication Not required.

Provenance and peer review Not commissioned; externally peer reviewed.

\section{REFERENCES}

1 Lane DP, Crawford LV. T antigen is bound to a host protein in SV49-transformed cells. Nature 1979:278:261-3.

2 Linzer DI, Levine AJ. Characterization of a 54K dalton cellular SV40 tumor antigen present in SV40-transformed cells and uninfected embryonal carcinoma cells. Cell 1979;17:43-52.

3 Lane DP. P53, guardian of the genome. Nature 1992;358:15-16.

4 Oren M. Decision making by p53: life, death and cancer. Cell Death Differ 2003;10:431-42.

5 Peller S, Rotter V. TP53 in hematological cancer: low incidence of mutations with significant clinical relevance. Hum Mutat 2003;21:277-84.

6 Brady CA, Attardi LD. P53 at a glance. J Cell Sci 2010;123:2527-32.

7 Zauberman A, Barak Y, Ragimov N, et al. Sequence-specific DNA binding by $p 53$ : identification of target sites and lack of binding to p53 - MDM2 complexes. Embo J 1993;12:2799-808.

8 Rippin TM, Freund SMV, Veprintsev DB, et al. Recognition of DNA by p53 core domain and location of intermolecular contacts of cooperative binding. J Mol Biol 2002:319:351-8

9 Menendez D, Inga A, Resnick MA. The expanding universe of p53 targets. Nat Rev Cancer 2009;9:724-37.

10 Burns TF, El-Deiry WS. Microarray analysis of p53 target gene expression patterns in the spleen and thymus in response to ionizing radiation. Cancer Biol Ther 2003:2:431-43

11 Clarke AR, Purdie CA, Harrison DJ, et al. Thymocyte apoptosis induced by p53dependent and independent pathways. Nature 1993;362:849-52.

12 Levine AJ, Oren M. The first 30 years of $\mathrm{p} 53$ : growing ever more complex. Nat Rev Cancer 2009:9:749-58

13 Olivier Met al. The clinical value of somatic TP53 gene mutations in 1,794 patients with breast cancer. Clin Cancer Res 2006;12:1157-67.

14 Govindan R, Weber J. TP53 mutations and lung cancer: not all mutations are created equal. Clin Cancer Res 2014;17:4419-21.

15 Parikh N, Hilsenbeck S, Creighton CJ, et al. Effects of TP53 mutational status on gene expression patterns across 10 human cancer types. J. Pathol. 2014;232:522-33.

16 Malkin D. P53 and the Li-Fraumeni syndrome. Cancer Genet Cytogenet 1993;66:83-92.

17 Liu Y, Chen C, Xu Z, et al. Deletions linked to TP53 loss drive cancer through p53independent mechanisms. Nature 2016;531:471-5.

18 Dittmer D, Pati S, Zambetti G, et al. Gain of function mutations in p53. Nat Genet 1993:4:42-6.

19 Gaidano G, Ballerini P, Gong JZ, et al. P53 mutations in human lymphoid malignancies: association with Burkitt lymphoma and chronic lymphocytic leukemia. Proc Natl Acad Sci U S A 1991:88:5413-7.

20 Landau DA, Carter SL, Stojanov P, et al. Evolution and impact of subclonal mutations in chronic lymphocytic leukemia. Cell 2013;152:714-26.
21 Dores GM, Anderson WF, Curtis RE, et al. Chronic lymphocytic leukaemia and small lymphocytic lymphoma: overview of the descriptive epidemiology. $\mathrm{Br}$ I Haematol 2007;139:809-19.

22 Hallek M, Cheson BD, Catovsky D, et al. iwCLL guidelines for diagnosis, indications for treatment, response assessment, and supportive management of CLL. Blood 2018:131:2745-60

23 Eichhorst B, Robak T, Montserrat E, et al. Chronic lymphocytic leukaemia: ESMO clinical practice guidelines for diagnosis, treatment and follow-up. Ann Oncol 2015;26(suppl 5):v78-84.

24 Schuh AH, Parry-Jones N, Appleby N, et al. Guideline for the treatment of chronic lymphocytic leukaemia: a british Society for haematology guideline. Br J Haematol 2018:182:344-59.

25 Juliusson G, Robèrt KH, Ost A, et al. Prognostic information from cytogenetic analysis in chronic B-lymphocytic leukemia and leukemic immunocytoma. Blood 1985:65:134-41.

26 Döhner H, Stilgenbauer S, Benner A, et al. Genomic aberrations and survival in chronic lymphocytic leukemia. N Engl J Med 2000;343:1910-6.

27 Hallek M, Cheson BD, Catovsky D, et al. Guidelines for the diagnosis and treatment of chronic lymphocytic leukemia: a report from the International Workshop on chronic lymphocytic leukemia updating the National cancer Institute-Working group 1996 guidelines. Blood 2008;111:5446-56.

28 Zenz T, Eichhorst B, Busch R, et al. TP53 mutation and survival in chronic lymphocytic leukemia. J Clin Oncol 2010;29:4473-9.

29 Rossi D, Cerri M, Deambrogi C, et al. The prognostic value of TP53 mutations in chronic lymphocytic leukemia is independent of Del17p13: implications for overall survival and chemorefractoriness. Clin Cancer Res 2009:15:995-1004.

30 Gonzalez D, Martinez P, Wade R, et al. Mutational Status of the TP53 Gene As a Predictor of Response and Survival in Patients With Chronic Lymphocytic Leukemia: Results From the LRF CLL4 Trial. JCO 2011;29:2223-9.

31 Malcikova J, Smardova J, Rocnova L, et al. Monoallelic and biallelic inactivation of TP53 gene in chronic lymphocytic leukemia: selection, impact on survival, and response to DNA damage. Blood 2009;114:5307-14.

32 Zenz T, Häbe S, Denzel T, et al. Detailed analysis of p53 pathway defects in fludarabine-refractory chronic lymphocytic leukemia (CLL): dissecting the contribution of 17p deletion, TP53 mutation, p53-p21 dysfunction, and miR34a in a prospective clinical trial. Blood 2009;114:2589-97.

33 Malcikova J, Pavlova S, Kozubik KS, et al. TP53 mutation analysis in clinical practice: lessons from chronic lymphocytic leukemia. Hum Mutat 2014;35:663-71.

34 Hallek M, Fischer K, Fingerle-Rowson G, et al. Addition of rituximab to fludarabine and cyclophosphamide in patients with chronic lymphocytic leukaemia: a randomised, open-label, phase 3 trial. Lancet 2010;376:1164-74.

35 Stilgenbauer S, Eichhorst B, Schetelig J, et al. Venetoclax in relapsed or refractory chronic lymphocytic leukaemia with 17p deletion: a multicentre, open-label, phase 2 study. Lancet Oncol 2016:17:768-78.

36 O'Brien S, Jones JA, Coutre SE, et al. Ibrutinib for patients with relapsed or refractory chronic lymphocytic leukaemia with 17p deletion (RESONATE-17): a phase 2, openlabel, multicentre study. Lancet Oncol 2016;17:1409-18.

37 Brown JR, Byrd JC, Coutre SE, et al. Idelalisib, an inhibitor of phosphatidylinositol 3-kinase p1108, for relapsed/refractory chronic lymphocytic leukemia. Blood 2014:123:3390-7.

38 Catovsky D, Richards S, Matutes E, et al. Assessment of fludarabine plus cyclophosphamide for patients with chronic lymphocytic leukaemia (the LRF CLL4 trial): a randomised controlled trial. Lancet 2007;370:230-9.

39 Malcikova J, Tausch E, Rossi D, et al. ERIC recommendations for TP53 mutation analysis in chronic lymphocytic leukemia — update on methodological approaches and results interpretation. Leukemia 2018;32:1070-80

40 Guièze R, Wu CJ. Genomic and epigenomic heterogeneity in chronic lymphocytic leukemia. Blood 2015;126:445-53.

41 Fernandez-Mercado M, Burns A, Pellagatti A, et al. Targeted re-sequencing analysis of 25 genes commonly mutated in myeloid disorders in del( $5 q)$ myelodysplastic syndromes. Haematologica 2013;98:1856-64.

42 Baliakas P, Hadzidimitriou A, Sutton L-A, et al. Recurrent mutations refine prognosis in chronic lymphocytic leukemia. Leukemia 2015;29:329-36.

43 Papaemmanuil E, Gerstung M, Malcovati L, et al. Clinical and biological implications of driver mutations in myelodysplastic syndromes. Blood 2013;122:3616-27.

44 Metzker ML. Sequencing technologies - the next generation. Nature Reviews Genetics 2010;11:31-46.

45 Wren D, Walker BA, Brüggemann M, et al. Comprehensive translocation and clonality detection in lymphoproliferative disorders by next-generation sequencing. Haematologica 2017:102:e57-60.

46 Black JS, Salto-Tellez M, Mills KI, et al. The impact of next generation sequencing technologies on haematological research - a review. Pathogenesis 2015;2:9-16

47 Rossi D, Khiabanian H, Spina V, et al. Clinical impact of small TP53 mutated subclones in chronic lymphocytic leukemia. Blood 2014;123:2139-47.

48 Landau DA, Tausch E, Taylor-Weiner AN, et al. Mutations driving CLL and their evolution in progression and relapse. Nature 2015;526:525-30. 